\title{
Pre-Operative Assessment and Education
}

\author{
Rozina Barkat Ali, Nasreen S. Lalani, Amina Malik \\ The Aga Khan University, Karachi, Pakistan \\ Email: anamika_zhs@yahoo.com
}

Received August 18, 2011; revised October 13, 2011; accepted December 6, 2011

\begin{abstract}
Introduction: Surgery is a major event in an individual's life. The complete surgical episode is known as perioperative period. Perioperative nursing in general includes three phases; pre-operative, intra-operative and post-operative. The first and initial phase (pre-operative) involves the rendering of nursing care to the patients who are planned to undergo surgery (Spry, 2005) [1]. It was evident through literature that during this phase, assessment and education of the patient is the prime responsibility of health care providers to minimize the risk during the surgery and to have better outcomes of the patients. Hence, a seven weeks project was initiated at surgical care units of Aga Khan University Hospital, Karachi, Pakistan. In this project, based on the need assessment, education sessions were conducted for the health care workers which were followed by the distribution of flash cards for their references. In addition, file review and pre operative patient's interview was conducted for the outcome evaluation. Purpose: To create awareness among healthcare workers to minimize the risk of morbidity and mortality of patients undergoing surgery and to reinforce nurses of surgical areas for the accurate assessment and education of patients, undergoing surgery. Methodology: All three surgical care units of the University teaching hospital were selected as project site and to conduct the project, permission and verbal consent was obtained from manager of these units. A total of 30 patients undergoing surgery were included in the project and were followed for their complete pre-operative assessment and education by nurses and other health care workers. For the data collection, a tool for pre operative assessment and education was developed. Based on the assessment, altogether three educational sessions were conducted for all health care workers working in the surgical care areas. Data was tabulated in Excel and percentages were calculated to analyze the data of before and after the education sessions. Results: Results revealed that education sessions increased the health care worker's knowledge for assessing all the necessary components of a patient before surgery. Additionally, these sessions enhanced nurses' awareness regarding the risks the patients might undergo before and after the surgery and how to prevent those risks through a thorough assessment and education of preoperative patients. Conclusion: Nurses and other health care providers should perform a complete and thorough assessment and provide necessary education to patients' undergoing surgery in order to reduce the bounce back rate from operating room and to avoid any kind of risk for their patients undergoing for any surgical procedure.
\end{abstract}

Keywords: Preoperative; Assessment; Education; Anesthesia; Surgery

\section{Introduction}

During the course of Senior Electives (practicum based course) in Post RN baccalaureate program, students get an opportunity to learn and work at their area of interests. I selected the field of management for my practicum experience and got a chance to work with manager of surgical and psychiatric unit at the Aga Khan University Hospital, Karachi, Pakistan (AKUH, K, P). During the course, it was expected to identify issues within the practice setting and select priority issue for practice based project. Major problem identified was related to the provision of Perioperative nursing care. Perioperative nursing in general includes three phases; pre-operative, intra-operative and post-operative. The first and initial phase (pre-operative) of Perioperative nursing involves the rendering of nursing care to the patients who are planned to undergo surgery (Spry, 2005) [1]. It was evident through literature that during this phase assessment and education of the patient is the prime responsibility of health care providers to minimize the risk during the surgery and to have better outcomes of the patients. Preoperative primary care is associated with minimal perioperative morbidities and decrease stay of patients at hospital (“AAGBI safety guidelines", 2010) [2]. On the basis of observations and literature support "Inappropriate Assessment and Education of Pre-Operative Patients" was selected as a priority problem for the project. The purpose of this project was to reinforce nurses of surgical areas for the accurate assessment and education of patients, undergoing surgery. 


\section{Assessment}

During the rounds of surgical areas, it was identified that seven patients were bounced back from OR without surgery during last three months, due to improper assessment of Nurse, physician or anesthesiologist which included lack of review of pulmonologist/cardiac consults, increased level of INR, low hemoglobin levels, low platelet counts and medication error that is patient's anti platelet drug dose was not hold before surgery. These were the unavoidable reasons that should be considered by the health care provider to ensure patient safety and to minimize the burden of cost by reducing the patient's hospital stay. According to Barnett (2005), Lack of preoperative assessment results in delay of surgery or perioperative complications that increases the stay of patient at hospital [3]. Finally, this problem was selected for the practice based project.

\section{Methodology}

For in-depth assessment of the problem, a pre-operative assessment and teaching evaluation tool was developed. 28 preoperative adult patients undergoing planned surgery were followed for their complete pre-operative assessment and education. For the collection of data, patients were interviewed and their files were reviewed. After data collection, data was analyzed using Microsoft Excel and was presented in the form of graphs. Table 1 describes the analysis of data of preoperative patient's assessment. It revealed that $21.4 \%$ of the patient's anesthesia clearance was not given before surgery and 53.5\% of the patient's laboratory tests were not checked. $75 \%$ patient's who were having allergies with any food or medication was not documented in patient's files. In addition, infectious diseases of $83 \%$ of the patients were not been documented which can be a risk for patient as well as for health care workers.

The above data exhibits that patients who were undergoing surgery are at risk of developing complications as they have not been assessed accurately before surgery. Table 2 describes the analysis of data of preoperative patient's education.

Through the above analysis, it was evident that nurses, doctors and anesthesiologist were not doing pre-operative patients' assessment and education properly which could lead to complications or delay in surgery.

\section{Literature Review}

According to Bray (2006), the aim of preoperative assessment is to reduce morbidity and mortality associated with surgery, prevent unnecessary cancellations and reduce hospital stay in surgical patients [4]. Whereas, the major aim of preoperative education is to decrease pa-
Table 1. Data analysis of assessment of pre-operative patients.

\begin{tabular}{|c|c|c|c|}
\hline \multicolumn{2}{|c|}{ Components of assessment } & Yes & No \\
\hline \multicolumn{2}{|c|}{ Consent form signed } & $92.8 \%$ & $7.14 \%$ \\
\hline \multicolumn{2}{|c|}{ Anesthesia clearance given } & $78.5 \%$ & $21.4 \%$ \\
\hline \multicolumn{2}{|c|}{ Laboratory results checked } & $46.4 \%$ & $53.5 \%$ \\
\hline \multicolumn{2}{|c|}{ Medication reviewed for hold } & $100 \%$ & $0 \%$ \\
\hline \multicolumn{2}{|c|}{ Allergies documented } & $25 \%$ & $75 \%$ \\
\hline \multicolumn{2}{|c|}{ Patient's valuables removed } & $82.1 \%$ & $17.8 \%$ \\
\hline \multicolumn{2}{|c|}{ Hibiscrub bath given } & $75 \%$ & $25 \%$ \\
\hline \multirow{3}{*}{$\begin{array}{l}\text { Pre-operative } \\
\text { medication }\end{array}$} & Ordered & $96.2 \%$ & $3.7 \%$ \\
\hline & Entered & $59.2 \%$ & $40.7 \%$ \\
\hline & Given & $85.1 \%$ & $14.8 \%$ \\
\hline \multirow{3}{*}{$\begin{array}{l}\text { Accompany to } \\
\text { operating room }\end{array}$} & Medication & $100 \%$ & $0 \%$ \\
\hline & Stockings/others & $100 \%$ & $0 \%$ \\
\hline & X-ray, MRI, CT scan, CD & $100 \%$ & $0 \%$ \\
\hline \multicolumn{2}{|c|}{$\begin{array}{l}\text { Infectious Disease documented } \\
\text { (Hepatitis A-E, AIDs, others) }\end{array}$} & $17 \%$ & $83 \%$ \\
\hline \multirow{2}{*}{ Vital signs } & Checked & $89.2 \%$ & $10.7 \%$ \\
\hline & Documented & $85.7 \%$ & $14.2 \%$ \\
\hline
\end{tabular}

Table 2. Data analysis of education of pre-operative patients.

\begin{tabular}{cccc}
\hline \multicolumn{2}{c}{ Components of teaching } & Yes & No \\
\hline \multirow{2}{*}{ Procedure } & Given & $53.5 \%$ & $46.4 \%$ \\
& Documented & $60.7 \%$ & $39.2 \%$ \\
Fasting time and duration & Given & $82.1 \%$ & $17.8 \%$ \\
& Documented & $50 \%$ & $50 \%$ \\
Pain management & Given & $0 \%$ & $100 \%$ \\
& Documented & $50 \%$ & $50 \%$ \\
Surgery related exercises & Given & $0 \%$ & $100 \%$ \\
& Documented & $67.8 \%$ & $32.1 \%$ \\
\hline
\end{tabular}

tient's anxiety by providing information on procedure, pain management, postoperative discomforts and impending signs of infection. Moreover, good preoperative assessment and screening improves the overall patient care and efficiency of the operating list (The Royal College of Anesthesia, 2009) [5]. The above literature specifies the significance of assessment and teaching in preoperative patients. Furthermore, analysis of each component revealed that nursing staff requires education and reinforcement in this regard.

In this project, model of professional perioperative 
nursing practice [6] was inculcated. It represents the interacting roles portrayed by the professional nurse during the phases of perioperative period (Figure 1).

I integrated the first phase of this model in my project as my project was related to preoperative phase only. The model states that nurses play different roles in each phase of perioperative nursing. In the initial phase (preoperative phase), nurse act as a leader change agent as well as teacher and is responsible for thorough assessment and education of the patients undergoing surgery.

\subsection{Leader Change Agent}

The model reflects that the role of preoperative nurse is to do complete physical examination of a patient, take patient's complete history, assess patient for presence of infectious disease, review results of diagnostic and laboratory tests. If the above roles are accurately performed by the preoperative nurse, she can contribute in decreasing the chances for delay or postponing of surgeries. In addition, patient would be having decrease risk for developing complications intra-operatively and postoperatively. During the assessment phase of the project, it was evident that the nursing staffs were not performing their role as a leader change agent as they were not doing proper assessment of preoperative patients as a result patients were bouncing back from operating room. During the implementation phase of the project, proper assessment of the patients was reinforced to the nursing staff of the surgical units and was evaluated on an ongoing basis by the Clinical Nurse Instructor (CNI) of the units.

\subsection{Teacher}

Another role of preoperative nurse as an educator was highlighted in the model. Being a teacher, nurse must identify the patient's need for information on every aspect of surgical care. Moreover, the mode of communication and patient's level of understanding should be assessed before educating the patient or family. This will help patients in managing their stress and anxiety. However, during the assessment of the project, it was identified that patients were not explained about the procedure and other details. This role performance was also reinforced during the implementation phase of the project and was evaluated by me and the CNIs of the units.

This model assisted me to reinforce two major roles of preoperative nurse in my project and each step of the project was based on the performance of the above described roles.

\section{Implementation}

Once the data was analyzed, an action plan was developed for the implementation and evaluation of the project. For implementation of the project, three in-service sessions were conducted in a month. Each session was of one hour. Session was attended by all the registered nurses, critical care technicians and nursing assistants of surgical units. Furthermore, a flyer was pasted on the notice boards of all surgical units and hanging flash cards were distributed to all registered nurses and critical care

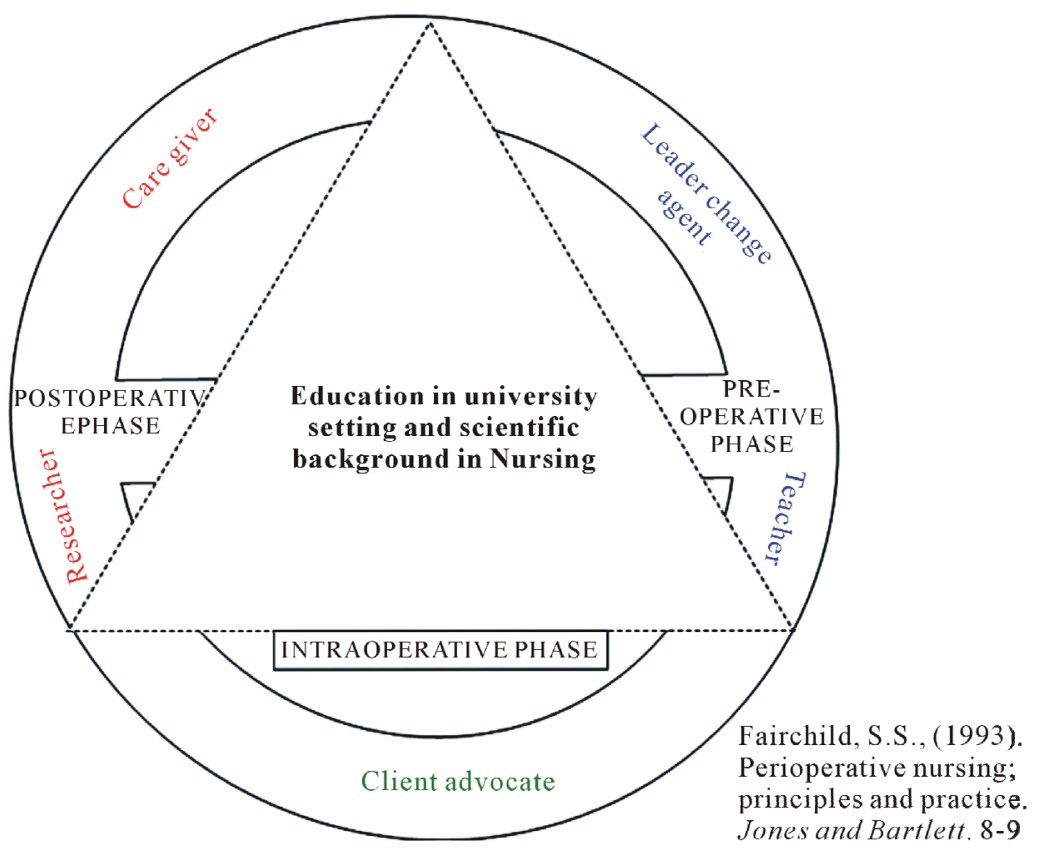

Figure 1. Professional perioperative nursing practice model. 
technicians that state the important components of preoperative assessment and evaluation so that they can review key points while caring for surgical patients during preoperative phase. During the session, clinical nurse instructors were invited so that they can educate and reinforce the staff on an ongoing basis. Moreover, a complete module on "Preoperative assessment and Education” was prepared and was kept in all the surgical units for sustainability of the project.

\section{Evaluation}

Post hoc analysis was done to analyze the difference in the knowledge, skills and attitudes of the staff. The same tool which was utilized for assessment was then reutilized for evaluation and results were analyzed in the form of tables. Table 2 illustrates the difference in pre and post analysis of the project. It shows that after implementation of the project $89.6 \%$ patient's anesthesia clearance was given by the anesthesiologist before surgery. $82.7 \%$ of the patient's laboratory results were checked. $50 \%$ of the patient's allergies and infectious diseases were documented respectively.

Data analysis of evaluation (Table 3) reveals that in each component of assessment percentages were raised except the component of medication reviewed for hold. This increase in percentages evident that the nursing staffs are performing their role of leader change agent to greater extent and this can minimize the delays and decreases the risk of developing complications.

Analyses in Table 4 reflect that after the phase of implementation, there is an increase in the number of patients who received teaching on the above mentioned component. This shows that the nursing staffs are effectively performing the role of a teacher in preoperative phase. Due to the constraint of time, summative evaluation was not possible. However, the tool for evaluation of the project was handed over to clinical nurse instructors so that the project's summative evaluation can be done.

\section{Limitations}

There were certain limitations that I faced during the project. Due to less time, summative evaluation of the project was not possible. Moreover, due to shift duties of the staff, some of the staff was not able to attend the session; however, $80 \%$ of the staff was covered for the sessions.

\section{Recommendations}

It is strongly recommended that other than the surgical unit, this project should be implemented in other units of the hospital such as cardiac surgery, and maternal and child health units. A monitoring mechanism should be in
Table 3. Pre and post intervention analysis of pre-operative assessment.

\begin{tabular}{|c|c|c|c|}
\hline \multicolumn{2}{|c|}{ Components of assessment } & Pre-intervention & Post intervention \\
\hline \multicolumn{2}{|c|}{ Consent form signed } & $92.8 \%$ & $96.5 \%$ \\
\hline \multicolumn{2}{|c|}{ Anesthesia clearance given } & $78.5 \%$ & $89.6 \%$ \\
\hline \multicolumn{2}{|c|}{ Laboratory results checked } & $46.4 \%$ & $82.7 \%$ \\
\hline \multicolumn{2}{|c|}{ Medication reviewed for hold } & $100 \%$ & $85.6 \%$ \\
\hline \multicolumn{2}{|c|}{ Allergies documented } & $25 \%$ & $50 \%$ \\
\hline \multicolumn{2}{|c|}{ Patient's valuables removed } & $82.1 \%$ & $93 \%$ \\
\hline \multicolumn{2}{|c|}{ Hibiscrub bath given } & $75 \%$ & $96.5 \%$ \\
\hline \multirow{3}{*}{$\begin{array}{l}\text { Pre-operative } \\
\text { medication }\end{array}$} & Ordered & $96.2 \%$ & $100 \%$ \\
\hline & Entered & $59.2 \%$ & $100 \%$ \\
\hline & Given & $85.1 \%$ & $95.4 \%$ \\
\hline \multirow{3}{*}{$\begin{array}{l}\text { Accompany } \\
\text { to OR }\end{array}$} & Medication & $100 \%$ & $100 \%$ \\
\hline & Stockings/others & $100 \%$ & $100 \%$ \\
\hline & $\begin{array}{l}\text { X-ray, MRI, CT } \\
\text { scan, CD }\end{array}$ & $100 \%$ & $100 \%$ \\
\hline \multicolumn{2}{|c|}{$\begin{array}{l}\text { Infectious Disease documented } \\
\text { (Hepatitis A-E, others) }\end{array}$} & $17 \%$ & $50 \%$ \\
\hline \multirow{2}{*}{ Vital signs } & Checked & $89.2 \%$ & $96.5 \%$ \\
\hline & Documented & $85.7 \%$ & $96.5 \%$ \\
\hline
\end{tabular}

Table 4. Pre and post intervention analysis of pre-operative education.

\begin{tabular}{cccc}
\hline \multicolumn{2}{c}{ Components of teaching } & Yes & No \\
\hline \multirow{2}{*}{ Procedure } & Given & $53.5 \%$ & $96.5 \%$ \\
& Documented & $60.7 \%$ & $93.1 \%$ \\
Fasting time and duration & Given & $82.1 \%$ & $96.5 \%$ \\
& Documented & $50 \%$ & $79.3 \%$ \\
Pain management & Given & $0 \%$ & $82.7 \%$ \\
& Documented & $50 \%$ & $82.7 \%$ \\
Surgery related exercises & Given & $0 \%$ & $65.5 \%$ \\
& Documented & $67.8 \%$ & $72.4 \%$ \\
\hline
\end{tabular}

place to assist and ensure the quality care provided by the staff. Continuous reinforcement and educational sessions for the staff on this particular area should be regularly done by the CNIs. There should be a record of patients who bounce back from theater in a month with specifications. Finally, surgical checklist should be reviewed and modified for necessary changes to ensure the safety and quality care of the patients. 


\section{REFERENCES}

[1] C. Spry, "Essentials of Perioperative Nursing," Jones and Bartlett, Sudbury, 2005, pp. 1-2

[2] AAGBI Safety Guideline, "Pre-Operative Assessment and Patient Preparation. The Role of the Anaesthetist," The Association of Anaesthetists of Great Britain and Ireland, London, 2010.

[3] J. S. Barnet, “An Emerging Role for Nurse Practitioners Preoperative Assessment," Association of Perioperative Registered Nurses Journal, 2010
http://findarticles.com/p/articles/mi_m0FSL/is_5_82/ai_n 15866288/?tag=rbxcra.2.a.44

[4] A. Bray, "Preoperative Nursing Assessment If the Surgical Patient," Nursing Clinics of North America, Vol. 41, No. 2, 2006, pp. 135-150. doi:10.1016/j.cnur.2006.01.006

[5] The Royal College of Anesthesia, "Guidance on the Provision of Anesthetic Services for Preoperative Care,” The Royal College of Anesthesia, London, 2009, pp. 1-4.

[6] S. S. Fairchild, "Perioperative Nursing; Principles and Practice,” Jones and Bartlett, Sudbury, 1993, pp. 8-9. 